\title{
Heptemerones $A \sim G$, Seven Novel Diterpenoids from Coprinus heptemerus: Producing Organism, Fermentation, Isolation and Biological Activities
}

\author{
Melanie Kettering, Carola Valdivia, Olov Sterner, Heidrun Anke, Eckhard Thines
}

Received: March 18, 2005 / Accepted: June 6, 2005

(C) Japan Antibiotics Research Association

\begin{abstract}
Seven novel diterpenoids, named heptemerones $A \sim G$, were isolated from the broth of submerged cultures of Coprinus heptemerus, a basidiomycete which previously had not been known to produce secondary metabolites. The compounds were purified by solid phase extraction and silica gel chromatography followed by preparative HPLC. Among the biological activities the inhibition of fungal germination was the most potent, and depended highly on the composition of the assay medium. In water, inhibition occurred at $5 \sim 10$ fold lower concentrations as compared to complex media. Heptemerone $G$ was the most active compound with MICs starting at $1 \mu \mathrm{g} / \mathrm{ml}$. Four of the antifungal compounds exhibited plant protective activity in a leaf segment assay using Magnaporthe grisea as the pathogen. Growth of yeasts and bacteria was hardly affected. Cytotoxic activities were moderate and only heptemerone $\mathrm{D}$ was phytotoxic.
\end{abstract}

Keywords Coprinus heptemerus, heptemerones, diterpenes, inhibition of conidial germination, Magnaporthe grisea

H. Anke (Corresponding author), M. Kettering: Institute for Biotechnology and Drug Research (IBWF), Erwin-SchrödingerStrasse 56, D-67663 Kaiserslautern, Germany, E-mail: anke@ibwf.de

E. Thines (Corresponding author): University of Kaiserslautern, Department of Biotechnology, D-67663 Kaiserslautern, Germany, E-mail: thines@ibwf.de

O. Sterner, C. Valdivia: Division of Organic and Bioorganic Chemistry, University of Lund P.O.Box 124, S-22100 Lund, Sweden.

\section{Introduction}

In the course of our screening for novel plant protectants, Coprinus heptemerus was found to produce compounds which inhibited germination of conidia without interfering with mycelial growth of Magnaporthe grisea. The rationale behind this approach was to inhibit selectively infectionrelated differentiation in phytopathogenic fungi as described before [1 5]. So far no secondary metabolites have been described from $C$. heptemerus, a basidiomycete growing on rabbit dung [6]. Coprophilic fungi have been shown to be a good source for bioactive compounds in the past $[7 \sim 10]$, therefore this fungus was selected for the isolation and characterisation of the active principles. In this paper we describe the producing organism, its cultivation, the isolation of seven structurally related diterpenoids and their biological activities, while the structure elucidation and physico-chemical properties of the compounds are reported in a separate paper [11].

\section{Material and Methods}

Microorganisms

Coprinus heptemerus, strain D99052, was grown and kept on YMG-medium consisting of glucose $1 \%$, malt extract $1 \%$ and yeast extract $0.4 \%$ in tap water at $22^{\circ} \mathrm{C}$. For solid media $1.5 \%$ agar was added.

Magnaporthe grisea strain 70-15 was obtained from the Fungal Genetics Stock Centre, Kansas. The strain was grown on CM medium as described by Talbot et al. [12]. 
Conidia were harvested from plates incubated at $28^{\circ} \mathrm{C}$ in a 16-hour-light and 8-hour-dark cycle. During the dark period the temperature was lowered to $24^{\circ} \mathrm{C}$.

\section{Fermentation}

Ten pieces cut from agar slants were transferred into a $2000 \mathrm{ml}$ Erlenmeyer flask containing $1000 \mathrm{ml}$ YMG medium. The flasks were incubated on a rotary shaker at $120 \mathrm{rpm}$ and $22^{\circ} \mathrm{C}$. Fermentation on a larger scale was carried out in a Biostat D-300 (Braun, Melsungen, Germany) containing 200 liters of YMG medium with stirring $(120 \mathrm{rpm})$ and aeration (30 liters air per minute) at $22^{\circ} \mathrm{C}$. To prevent foaming, silicone antifoam (Merck, Darmstadt) was added. The fermentor was inoculated with 5 liters of a well grown culture in the same medium. Daily samples were withdrawn and assayed for $\mathrm{pH}$, glucose and maltose content as well as for biological activity towards germination of $M$. grisea conidia. The culture broth was separated by filtration. Mycelia contained no active compounds were discarded. The culture broth from shake flasks was extracted with EtOAc, the organic phase dried with $\mathrm{Na}_{2} \mathrm{SO}_{4}$, concentrated in vacuo and the residue dissolved in $\mathrm{MeOH}$ to a concentration of $10 \mathrm{mg} / \mathrm{ml}$.

\section{Isolation of the Compounds}

The broth was passed through a column of DIAION HP21 resin in water (Mitsubishi Chemical Industry LTD, Dusseldorf, column size: $100 \times 440 \mathrm{~mm}$ ). The eluate was discarded. After washing with water (6 liters), the compounds were eluted with $\mathrm{MeOH}$ (8 liters), followed by $\mathrm{Me}_{2} \mathrm{CO}$ (6 liters). Upon concentration two crude products, CP I (20.4 g from the MeOH fraction) and CP II (19.4 g from the $\mathrm{Me}_{2} \mathrm{CO}$ fraction) were obtained. Chromatography on silica gel in cyclohexane - EtOAc (column size: $95 \times 220$ $\mathrm{mm}$; silica gel 60, 63 200 $\mu \mathrm{m}$ particle size; Merck, Darmstadt, Germany) and elution with cyclohexaneEtOAc with increasing amounts of EtOAc $(90: 10,80: 20$, $70: 30,60: 40,50: 50$ and $40: 60,2.5$ liters each) yielded three fractions with antifungal activity from each of the crude products. Final purification was achieved by preparative HPLC with a Jasco modular HPLC system (Gross-Umstadt, Germany) consisting of two binary pumps (PU-1586) and the multi-wavelength detector UV-1570M. The HPLC was fitted with a LiChrosorb RP-18 column $(250 \times 25 \mathrm{~mm}, 7 \mu \mathrm{m}$ particle size; Merck) and run at a flow rate of $7.5 \mathrm{ml} /$ minute and a linear gradient from water to $\mathrm{MeOH}$ in 90 minutes. Each run was performed with 120 $\mathrm{mg}$ aliquots of the active mixtures.

\section{Biological Assays}

Germination assay: Conidia from 10-day-old cultures were harvested. After centrifugation at $1000 \mathrm{~g}$ for 10 minutes the conidia were resuspended in distilled water to a concentration of $5 \times 10^{5}$ per $\mathrm{ml}$. The test was carried out in 24-well microtiter plates (Sarstedt, Nuremberg) with $2.5 \times 10^{4}$ conidia in $1 \mathrm{ml}$ of distilled water and incubation for 16 hours at $28^{\circ} \mathrm{C}$. Germinated conidia were counted with an inverted microscope (Leica DM IRB ). Tests were conducted in triplicates and 100 conidia were counted 3 times.

Leaf segment assay: Leaves from 16-day-old rice (Oryza sativa var. Tainong 67) or barley (Hordeum sativum var. Scarlett) seedlings were cut into $5 \mathrm{~cm}$ long segments and placed on water agar plates (1.5\% agar in tap water). $M$. grisea condia $\left(2.5 \times 10^{4} / \mathrm{ml}\right)$ and the test compounds were suspended in a $0.2 \%$ gelatine solution. Four droplets $(40 \mu \mathrm{l}$ for barley and $20 \mu \mathrm{l}$ for rice) of this solution were placed on each segment and the plates were incubated for 96 hours at $28^{\circ} \mathrm{C}$. The number and the size of the lesions were compared with the control without test compounds.

Antimicrobial activity was determined in the serial dilution test and the inhibition of growth of germinated seeds of Setaria italica and Lepidium sativum was tested as described before [13]. Bacteria were tested in nutrient broth (Difco), yeasts and fungi in YMG medium.

Cytotoxic activity was assayed as described previously [14] with slight modifications. Jurkat cells (DSMZ ACC 282) and Mono-Mac-6 cells (DSMZ ACC 124) were grown in RPMI 1640 medium (GIBCO, BRL), HeLa S3 (ATCC CCL 2.2) and Hep G2 (DSMZ ACC 180) cells in D-MEM (GIBCO, BRL), supplemented with $10 \%$ fetal calf serum (GIBCO, BRL), $65 \mu \mathrm{g} / \mathrm{ml}$ of penicillin $\mathrm{G}$ and $100 \mu \mathrm{g} / \mathrm{ml}$ of streptomycin sulphate. The assays contained $1 \times 10^{5}$ cells $/ \mathrm{ml}$ medium. The concentration at which cell proliferation was reduced by $50 \%$ is given as $\mathrm{IC}_{50}$ values.

\section{Results}

\section{Producing Organism}

The producing organism was isolated from fruiting bodies growing on rabbit dung. The features of the fruiting bodies and basidiospores corresponded with the description of Coprinus heptemerus M Lange \& AH Smith given by Orton and Watling [15]. On agar plates, especially upon addition of rabbit dung the culture produced tiny fruiting bodies with stipes $1.5 \sim 3 \mathrm{~cm}$ long and basidiocarps $0.3 \sim 0.5 \mathrm{~cm}$ in diameter. 


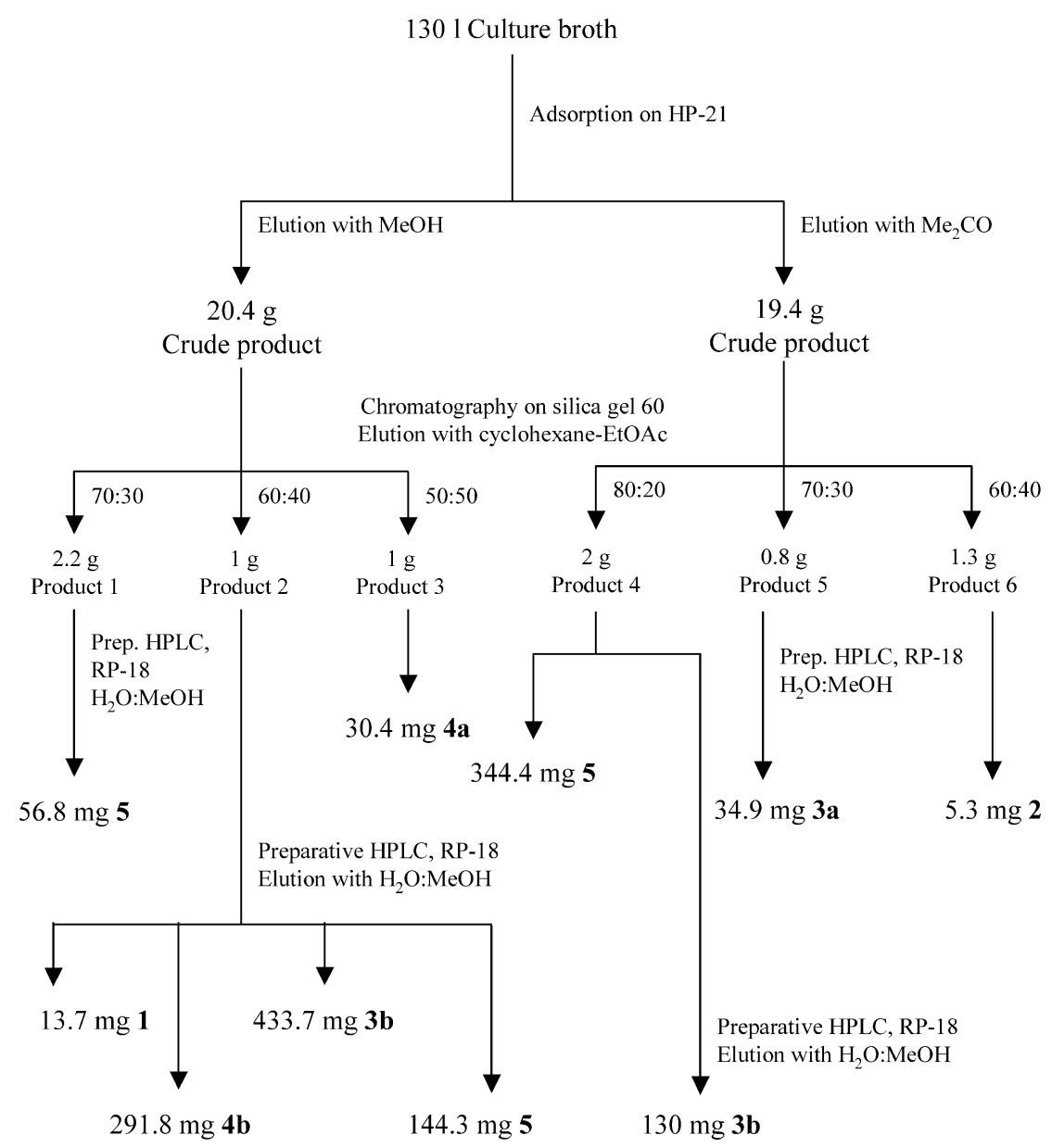

Fig. 1 Purification of heptemerones $A(\mathbf{1}) \sim G(\mathbf{5})$ from a culture broth of $C$. heptemerus.

Fermentation and Isolation of Compounds 1, 2, 3a, 3b, $4 \mathrm{a}, 4 \mathrm{~b}$, and 5

Eight different media were used for the evaluation of the production of the bioactive metabolites: malt medium ( $4 \%$ malt extract or $2 \%$ malt extract), potato - dextrose medium ( $2 \%$ glucose, $0.4 \%$ potato powder), $\mathrm{CM}$ medium, corn meal medium (corn meal 1\%, glucose $1 \%, \mathrm{KCl} 0.05 \%, \mathrm{NaNO}_{3}$ $0.05 \%, \mathrm{MgSO}_{4} \cdot 7 \mathrm{H}_{2} \mathrm{O} 0.05 \%, \mathrm{~K}_{2} \mathrm{HPO}_{4} 0.15 \%$ ), YMG medium, YMG medium with $0.4 \%$ glucose, and Czapek yeast medium [16]. Growth in corn meal and potato dextrose medium was rather slow and no bioactive compounds have been detected. Among the other media, YMG medium yielded the highest activity in the crude extracts. Therefore, this medium was chosen for the production and isolation of the compounds in a 200-liters fermentor. The fermentation was terminated after six days after exhaustion of the carbon sources. The active compounds were isolated from the broth as shown in Fig. 1. It is interesting to note that the composition of the heptemerone mixture was less complex when the fungus was grown in flasks. These crude extracts contained only compounds $\mathbf{3 b}, \mathbf{4 a}$ and $\mathbf{4 b}$. The concentrations of the single compounds, however, were much higher: $17.8 \mathrm{mg} /$ liter of $\mathbf{3 b}, 15.6 \mathrm{mg} / \mathrm{liter}$ of $\mathbf{4 a}$, and $47.5 \mathrm{mg} /$ liter $\mathbf{4 b}$ versus $4.2 \mathrm{mg} /$ liter of $\mathbf{1}, 2 \mathrm{mg} / \mathrm{liter}$ of $\mathbf{2}, 1.6 \mathrm{mg} / \mathrm{liter}$ of $\mathbf{3 a}$, $8.4 \mathrm{mg} /$ liter of $\mathbf{3 b}, 5.1 \mathrm{mg} /$ liter of $\mathbf{4 a}, 7.5 \mathrm{mg} /$ liter of $\mathbf{4 b}$, and $9.1 \mathrm{mg} /$ liter of $\mathbf{5}$ in the fermentor (for structures see Fig. 2).

\section{Biological Activities of Compounds 1, 2, 3a, 3b, 4a, 4b, and 5}

The antibacterial activities were very weak. Escherichia coli, Mycobacterium phlei and Arthrobacter citreus were not affected by any of the compounds. Compounds $\mathbf{3 a}, \mathbf{3 b}$ and 5 were bacteriostatic towards Pseudomonas fluorescens, Micrococcus luteus, Corynebacterium insidiosum, Bacillus brevis and B. subtilis at $20 \mu \mathrm{g} / \mathrm{ml}$. No activity towards Candida albicans and Candida glabrata up to $100 \mu \mathrm{g} / \mathrm{ml}$ was observed.

Mycelial growth of $M$. grisea was weakly affected at concentrations higher than $40 \mu \mathrm{g} / \mathrm{ml}$ of compounds 1, 2, 3a, 


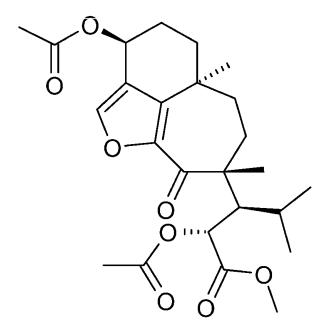

$A(1)$

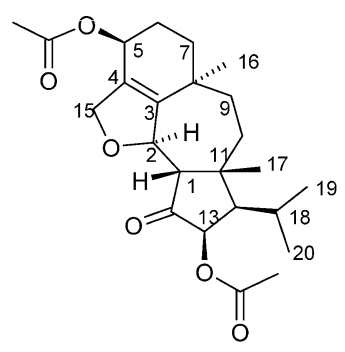

$B(2)$

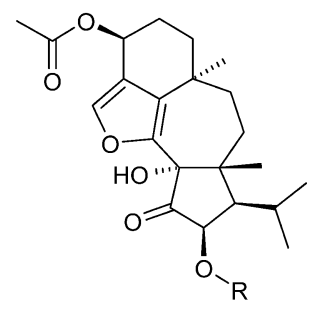

C (3a: $\left.\mathrm{R}=\mathrm{CH}_{3}\right)$ and $\mathrm{D}(\mathbf{3 b}: \mathrm{R}=\mathrm{Ac})$

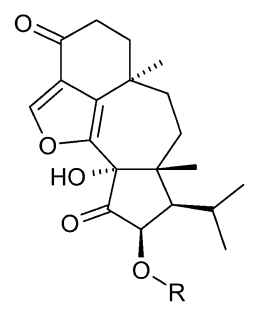

$E(4 a: R=H)$ and $F(4 b: R=A c)$

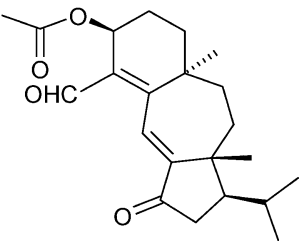

G (5)

Fig. 2 Structures of heptemerones $A(\mathbf{1}) \sim G(\mathbf{5})$

$\mathbf{3 b}, \mathbf{4 a}$, and $\mathbf{4 b}$, whereas compound $\mathbf{5}$ inhibited the growth at $10 \mu \mathrm{g} / \mathrm{ml}$.

The antifungal activities, measured as inhibition of spore germination, are given in Table 1. Activities in water were much higher as compared in YMG medium. Compound 5 was the most active one, followed by $\mathbf{3 a}, \mathbf{3 b}$ and $\mathbf{4 b}$. $M$. grisea and Colletotrichum graminicola were the most susceptible fungi. These four compounds also showed protective activity in the leaf segment assay with Oryza sativa and Hordeum sativum (Table 2).

Phytotoxic activities were only recorded for compound 3b towards $O$. sativa starting at $65 \mu \mathrm{g} / \mathrm{ml}$. At this concentration the shoot length was reduced by $85 \%$, while the root length was only weakly affected at $330 \mu \mathrm{g} / \mathrm{ml}$ (reduction by 50\%). The other compounds were not phytotoxic up to $330 \mu \mathrm{g} / \mathrm{ml}$; germination and growth of Lepidium sativum was not inhibited.

Cytotoxic activities, as shown in Table 3, varied according to the cell line used. Jurkat and Mono-Mac-6 cells were the most sensitive cells and HeLa S3 cells were hardly affected. Even so 5 showed the highest inhibition of proliferation, compound $\mathbf{1}$ was selectively cytotoxic.

No nematicidal activities towards Caenorhabditis elegans and Meloidogyne incognita were observed at concentrations up to $100 \mu \mathrm{g} / \mathrm{ml}$.

\section{Discussion}

Coprinus heptemerus, a tiny, coprophilous basidiomycete that is often overlooked, belongs to a rather large genus which is currently under revision [17]. Some species of the 350 that comprise the genus have been reported to produce bioactive secondary metabolites [18]. Especially $C$. quadrifidus, a prolific producer of polyines [19], and $C$. atramentarius [20] have thoroughly been investigated. But more than $90 \%$ of the species, however, remain to be examined for their secondary metabolite spectrum. $C$. heptemerus, the species investigated here, produced seven structurally related diterpenes which were named heptemerones $A \sim G(\mathbf{1}, \mathbf{2}, \mathbf{3 a}, \mathbf{3 b}, \mathbf{4 a}, \mathbf{4 b}$ and $\mathbf{5})$. These compounds are structurally not related to any of the metabolites reported from other Coprinus species. Compounds with the same carbon skeleton, the guanacastepenes, have been isolated from an endophyte of Daphnopsis americana [21, 22], which most probably belongs to the Basidiomycetes [23]. In contrast to Ascomycetes, Basidiomycetes are prolific producers of terpenoids including the dipterpenoids, heptemerones and guanacastepenes [24]. The latter were isolated due to their antibacterial activity whereas the antibacterial activity of 
Table 1 Antifungal activities of compounds $\mathbf{1}, \mathbf{2}, \mathbf{3 a}, \mathbf{3} \mathbf{b}, \mathbf{4 a}, \mathbf{4} \mathbf{b}$, and $\mathbf{5}$. Inhibition of germination of conidia, MIC represents the concentration at which no germination of the conidia was observed

\begin{tabular}{|c|c|c|c|c|c|c|c|}
\hline \multirow{2}{*}{ Test organism (medium) } & \multicolumn{7}{|c|}{$\mathrm{MIC}[\mu \mathrm{g} / \mathrm{ml}]$} \\
\hline & 1 & 2 & $3 a$ & $3 \mathbf{b}$ & $4 a$ & $4 b$ & 5 \\
\hline Bipolaris victoriae $\left(\mathrm{H}_{2} \mathrm{O}\right)$ & $>100$ & $>100$ & $>100$ & 100 & $>100$ & $>100$ & 20 \\
\hline Bipolaris victoriae (YMG) & $>100$ & $>100$ & $>100$ & 50 & $>100$ & $>100$ & 50 \\
\hline Botrytis cinerea $\left(\mathrm{H}_{2} \mathrm{O}\right)$ & $>100$ & 50 & 20 & 20 & $>100$ & 50 & 5 \\
\hline Botrytis cinerea (YMG) & $>100$ & $>100$ & 100 & 100 & $>100$ & 100 & 20 \\
\hline Colletotrichum graminicola $\left(\mathrm{H}_{2} \mathrm{O}\right)$ & $>100$ & $>100$ & 10 & 20 & $>100$ & 50 & 1 \\
\hline Colletotrichum graminicola (YMG) & $>100$ & $>100$ & 50 & 100 & $>100$ & 100 & 5 \\
\hline Drechslera oryzae $\left(\mathrm{H}_{2} \mathrm{O}\right)$ & $>100$ & $>100$ & 20 & 20 & $>100$ & 20 & 10 \\
\hline Drechslera oryzae (YMG) & $>100$ & $>100$ & $>100$ & $>100$ & $>100$ & $>100$ & 100 \\
\hline Fusarium solani $\left(\mathrm{H}_{2} \mathrm{O}\right)$ & $>100$ & - & 100 & 100 & $>100$ & $>100$ & 20 \\
\hline Fusarium solani (YMG) & $>100$ & $>100$ & $>100$ & 100 & $>100$ & $>100$ & 100 \\
\hline Magnaporthe grisea $\left(\mathrm{H}_{2} \mathrm{O}\right)$ & $>100$ & $>100$ & 10 & 20 & $>100$ & 20 & 1 \\
\hline Magnaporthe grisea (YMG) & $>100$ & $>100$ & 50 & 50 & $>100$ & 50 & 5 \\
\hline Ascochyta pisi (YMG) & $>100$ & $>100$ & $>100$ & $>100$ & $>100$ & $>100$ & 10 \\
\hline Aspergillus ochraceus (YMG) & $>100$ & $>100$ & $>100$ & $>100$ & $>100$ & $>100$ & 50 \\
\hline Cladosporium cladosporioides (YMG) & $>100$ & $>100$ & $>100$ & $>100$ & $>100$ & $>100$ & 20 \\
\hline Paecilomyces varioti (YMG) & $>100$ & $>100$ & $>100$ & $>100$ & $>100$ & $>100$ & 50 \\
\hline Penicillium notatum (YMG) & $>100$ & $>100$ & 50 & $>100$ & $>100$ & $>100$ & 20 \\
\hline Penicillium janczewskii (YMG) & $>100$ & $>100$ & $>100$ & $>100$ & $>100$ & $>100$ & 50 \\
\hline Phytophthora infestans (YMG) & $>100$ & $>100$ & $>100$ & $>100$ & $>100$ & $>100$ & $>100$ \\
\hline Septoria tritici (YMG) & $>100$ & $>100$ & $>100$ & $>100$ & $>100$ & 100 & 20 \\
\hline
\end{tabular}

Table 2 Antifungal activities of compounds $\mathbf{1}, \mathbf{2}, \mathbf{3 a}, \mathbf{3 b} \mathbf{3}, \mathbf{4 a}, \mathbf{4} \mathbf{b}$, and $\mathbf{5}$ in the leaf segment assay with Oryza sativa and Hordeum sativum and $M$. grisea as pathogen. MIC represents the concentration at which no lesions were observed after 96 hours

\begin{tabular}{lrrrrrrr}
\hline & \multicolumn{1}{c}{$M I C[\mu \mathrm{g} / \mathrm{ml}]$} \\
\cline { 2 - 8 } Test plant & $\mathbf{1}$ & $\mathbf{2}$ & $\mathbf{3 a}$ & $\mathbf{3 b}$ & $\mathbf{4 a}$ & $\mathbf{4 b}$ & $\mathbf{5}$ \\
\hline Oryza sativa & 100 & 100 & 10 & 20 & $>100$ & 10 & 1 \\
Hordeum sativum & 50 & 100 & 20 & $>50$ & $>100$ & 50 & 1 \\
\hline
\end{tabular}

the heptemerones is negligible compared to their antifungal and cytotoxic properties. The antibacterial inhibition zones for guanacastepene A however, the most active compound of the series, is in the same range as for the most active heptemerone i.e. compound $\mathbf{5}$. This compound, similar to guanacastepene $\mathrm{A}$, possesses two reactive groups, an $\alpha, \beta$ unsaturated aldehyde function and an $\alpha, \beta$-unsaturated ketone group, which are likely to be responsible for the biological activities since in the presence of cysteine the activities were abolished. Upon incubation with an equimolar amount of cysteine, after one hour the compound was no longer detectable (data not shown). This is in agreement with the non-selective inhibition of all macromolecular syntheses in E. coli by guanacastepene A [23]. Similar results were obtained for heptemerone G (5) in M. grisea (data not shown). With the exception of a weak inhibition of Candida albicans, no antifungal or cytotoxic activities have been reported for the guanacastepenes, while 
Table 3 Cytotoxicity of compounds $\mathbf{1}, \mathbf{2}, \mathbf{3 a}, \mathbf{3} \mathbf{b}, \mathbf{4 a}, \mathbf{4} \mathbf{b}$, and $\mathbf{5}$ towards Jurkat cells, Mono-Mac-6 cells, HeLa S3 cells, and HepG2 cells. $I C_{50}$ represents the concentration at which cell proliferations was reduced to $50 \%$

\begin{tabular}{crrrr}
\hline & \multicolumn{4}{c}{$\mathrm{IC}_{50}[\mu \mathrm{g} / \mathrm{ml}]$} \\
\cline { 2 - 5 } Compound & Jurkat & Mono-Mac-6 & HeLa S3 & HepG2 \\
\cline { 2 - 5 } & $5 \sim 10$ & 20 & 100 & $>100$ \\
$\mathbf{1}$ & 50 & $>100$ & $>100$ & $>100$ \\
$\mathbf{2}$ & $5 \sim 10$ & 10 & 20 & 20 \\
$\mathbf{3 a}$ & $20 \sim 50$ & 10 & 100 & $>100$ \\
$\mathbf{3 b}$ & 50 & 50 & $>100$ & 50 \\
$\mathbf{4 a}$ & 10 & 20 & 100 & 100 \\
$\mathbf{4 b}$ & 2 & 1 & 20 & 20 \\
$\mathbf{5}$ & & & & \\
\hline
\end{tabular}

none of the heptemerones affected the two Candida strains tested in this investigation. The selective cytotoxic activity of compound $\mathbf{1}$ towards cells growing in suspension is noteworthy as $\mathbf{1}$ showed no activity in the other test systems.

Acknowledgments We are grateful to Dr. J. Webster, University of Exeter, for the isolation and identification of the strain of $C$. heptemerus and to Dr. R. W. S. Weber for critically reading the manuscript. We thank R. Reiss and W. Schuck for expert technical assistance and the state of Rheinland-Pfalz for financial support.

\section{References}

1. Thines E, Anke H, Weber RWS. Fungal secondary metabolites as inhibitors of infection-related morphogenesis in phytopathogenic fungi. Mycol Res 108: 14-25 (2004)

2. Eilbert F, Anke H, Sterner O. Neobulgarones A F, new dimeric anthraquinones from cultures of Neobulgaria pura: Novel inhibitors of appressorium formation of Magnaporthe grisea. J Antibiot 53: 1123-129 (2000)

3. Thines E, Anke H, Sterner O. Inhibition of signal transduction leading to appressorium formation in Magnaporthe grisea by glisoprenins. In Developments in Plant Pathology, Volume 15: Advances in Rice Blast Research. Ed. Tharreau D et al., pp. 267-270, Kluwer Acad. Publisher, Dordrecht (2000)

4. Eilbert F, Thines E, Sterner O, Anke H. Fatty acids and their derivatives as modulators of appressorium formation in Magnaporthe grisea (Pyricularia oryzae). Biosci Biotechnol Biochem 63: 879-883 (1999)

5. Thines E, Eilbert F, Sterner O, Anke H. Inhibitors of appressorium formation in Magnaporthe grisea: A new approach to control rice blast disease. Pest Sci 54: 314-316 (1998)

6. Lange M, Smith AH. The Coprinus ephemerus group. Mycologia 45: 747-780 (1953)

7. Gloer JB. The chemistry of fungal antagonism and defense. Can J Bot 73 (Suppl 1): 1265-1274 (1995)

8. Ridderbusch DC, Weber RWS, Anke T, Sterner O. Tulasnein and podospirone from the coprophilous xylariaceous fungus Podosordaria tulasnei. Z Naturforsch 59c: 379-383 (2004)

9. Weber RWS, Meffert A, Anke H, Sterner O. Production of sordarin and related metabolites by the coprophilous fungus Podospora pleiospora in submerged culture and in its natural substrate. Mycol Res 109: 619-626 (2005)

10. Soman AG, Gloer JB, Koster B, Malloch D. Sporovexins $\mathrm{A} \sim \mathrm{C}$ and a new preussomerin analog: Antibacterial and antifungal metabolites from the coprophilous fungus Sporormiella vexans. J Nat Prod 62: 659-661 (1999)

11. Valdivia C, Kettering M, Anke H, Thines E, Sterner O. Diterpenoids from Coprinus heptemerus. Tetrahedron (submitted)

12. Talbot NJ, Ebbole DJ, Hamer JE. Identification and characterization of $M P G 1$, a gene involved in pathogenicity from the rice blast fungus Magnaporthe grisea. Plant Cell 5: 1575-1590 (1993)

13. Anke H, Bergendorff O, Sterner O. Assay of the biological activities of guaiane sesquiterpenoids isolated from the fruit bodies of edible Lactarius species. Food Chem Tox 27: 393-398 (1989)

14. Zapf S, Hossfeld M, Anke H, Velten R, Steglich W. Darlucins A and B, new isocyanide antibiotics from Sphaerellopsis filum (Darluca filum). J Antibiot 48: 36-41 (1995)

15. Orton PD, Watling R. Coprinaceae part 1: Coprinus. British Fungus Flora, 86-87, Royal Botanic Garden, Edinburgh (1979)

16. Pitt JI. An appraisal of identification methods for Penicillium species: novel taxonomic criteria based on temperature and water relations. Mycologia 65: 1135-1157 (1973)

17. Redhead SA, Vilgalys R, Moncalvo JM, Johnson J, Hopple JS. Coprinus Pers. and the disposition of Coprinus species sensu lato. Taxon 50: 203-241 (2001)

18. AntiBase 2003, Wiley John \& Sons, Inc. July 2003, ISBN 0471468401

19. Jones ERH, Stephenson JS. Chemistry of the higher fungi. 9. Polyacetylenic metabolites from Coprinus quadrifidus. J Chem Soc 2197-2203 (1959)

20. Lee IK, Jeong CY, Cho SM, Yun BS, Kim YS, Yu SH, Koshino H, Yoo ID. Illudins C2 and C3, new illudin C derivatives from Coprinus atramentarius ASI20013. J Antibiot 49: 821-822 (1996)

21. Brady SF, Singh MP. Janso JE, Clardy J. Guanacastepene, a fungal-derived diterpene antibiotic with a new carbon skeleton. J Am Chem Soc 122: 2116-2117 (2000)

22. Singh MP, Janso JE, Luckman SW, Brady SF, Clardy J, 
Greenstein M, Maiese WM. Biological activity of guanacastepene, a novel diterpenoid antibiotic produced by an unidentified fungus CR115. J Antibiot 53: 256-261 (2000)

23. Brady SF, Bondi SM, Clardy J. The guanacastepenes: a highly diverse family of secondary metabolites produced by an endophytic fungus. J Am Chem Soc 123: 9900-9901 (2001)

24. Lorenzen K, Anke T. Biologically active metabolites from basidiomycetes. Cur Org Chem 2: 329-364 (1998) 